This distortion may stand for an intentional obstruction, or may be caused by a natural and neutral source. As such, it recalls a comparison with hit- and anti-hit problems in game theory and the military science, prey and predator systems in ecology, pathogenic germs and antibodies in epidemiology, or an interrupted communication channel. Basically for its usefulness is, fo course, the assumed mode of interaction.

We shall just touch on this class of problems, and adopt the nomenclature of an attacker $\varphi$ and a defender $\psi$. For $\varphi, \mathbf{l} / \dot{t}$ is a measure of success in coming through a barrier: $\bar{t}_{\phi} / t$ equals the mean proportion of hits. For $\psi, \bar{t}$ is a measure of success on the part of the defence. For instance, given $\varphi(t)$, one may ask what $\psi(t)$ maximizes $\bar{t}$. Posing this question makes sense only, if constraints are made with regard to $\psi(t)$. A natural condition is that $\bar{t}_{\psi}$ is bounded: it measures the effort that $\psi$ is capable, or willing, to bring in for the defence. The same question can be formulated for a given $\psi(t)$, and asking what strategy $\varphi(t)$ minimizes $t$, again with a given $\bar{t}_{\varphi}$. Other additional constraints can be posited, perhaps with regard to $\sigma$ which has to do with the unpredictability of hitting. Also $\varphi$ and $\psi$ can supposed to be affected by a common, or different, external noise factor first, before the proper trial of strength. Other extensions present themselves, and they are of an interesting cybernetic nature with non-trivial solutions; but they are beyond the scope of this communication.

\section{Appendix}

Pooling of two processes, each consisting of a time series of impulses while the duration of the intervals between successive impulses in each series are independent of each other and identically distributed with a probability density function $p_{1}(t)$ and $p_{2}(t)$. Let $\bar{t}_{1}=\int_{0}^{\infty} t \cdot p_{1}(t) \cdot d t$, and $Q_{1}(t)=$ $\int_{t}^{\infty} p_{1}(\tau) \cdot d \tau ; \bar{t}_{2}$ and $Q_{2}(t)$ are analogously defined. If $p_{2 \cdot 1}(t)$ denotes the probability density function of the intervals between an impulse of the $p_{2}(t)$ process, and the next impulse of the $p_{1}(t)$ process, then $p_{2 \cdot 1}(t)=Q_{1}(t) / t_{1}$. A corresponding definition and expression holds for $p_{1 \cdot 2}(t)$. The interval distribution $\hat{p}(t)$ between the intervals between the impulses of the pooled process is then given by:

$$
\begin{aligned}
\hat{p}(t) & =\left\{p_{1}(t) \int_{i}^{\infty} Q_{2}(\tau) \cdot d \tau / \bar{t}_{2}+p_{1 \cdot 2}(t) \cdot Q_{1}(t)\right\} \bar{t}_{2} /\left(\bar{t}_{1}+\bar{t}_{2}\right)+ \\
& +\left\{p_{2}(t) \int_{i}^{\infty} Q_{1}(\tau) \cdot d \tau / \bar{t}_{1}+p_{2 \cdot 1}(t) \cdot Q_{2}(t)\right\} \bar{t}_{1} /\left(\bar{t}_{1}+\bar{t}_{2}\right) .
\end{aligned}
$$

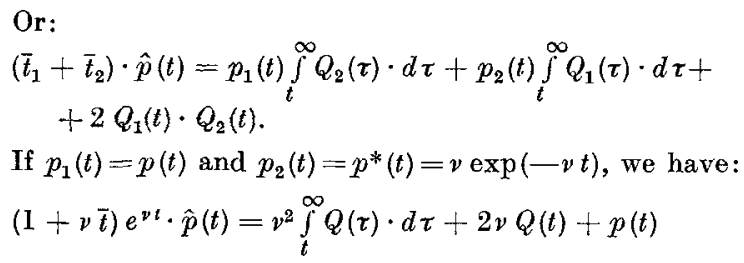

and

$$
\hat{p}(0)=\left\{v^{2} t+2 v+p(0)\right\} /(1+v \bar{t}) .
$$

References. Amassian, V. E., J. Macy jr. and H. J. WaLLER: Patterns of activity of simultaneously recorded neurons in midbrain reticular formation. Ann. N.Y. Acad. Sci. 89, 883-895 (1961). - BISHOP, P. O., W.R. LeVICK, and W.O. WrLlidaMS: Statistical analysis of the dark discharge of lateral geniculate neurons. J. Physiol, (Lond.) 170, 598-6I2 (1964). Cox, D. R., and W. L. SMrry: On the superposition of renewal processes. Biometrika 41, 91-99 (1954). - Feller, W.: On the integral equation of renewal theory. Ann. Math. Stat. 12, 243-267 (1941). - FeTz, E. E., and G. L. Gerstein: An RC model for spontaneous activity of single neurons. Quart. Progr. Rep., M.I.T. 71, 249-257 (1963). - Gerstein, G. L., and B. MANDELBRot: Random walk models for the spike activity of a single neuron. Biophys. J. 4, $41-68$ (1964). - Herz, A., O. CReUtzFeldT, and J. Fuster: Statistische Eigenschaften der Neuronenaktivität im ascendierenden visuelien System. Kybernetik 2, 61-71 (1964). - HuBEL, D. H., and T. N. WIESEL: Integrative action in the cat's lateral geniculate body. J. Physiol. (Lond.) 155, 385-398 (1961). - Moushegian, G., A. RUPERT, and M.A. Whitcoms: Brain-stem neuronal response patterns to monaural and binaural tones. J. Neuro. physiol. 27, 1174-1191 (1964). - NEGISHI, K., E. S. Lu, and M. VerzeAno: Neuronal activity in the lateral geniculate body and the nucleus reticularis of the thalamus. Vision Res. 1, 343-353 (1962). - Pkrkel, D. H., G. P. Moore, and J. P. Skgundo: Continuous-time simulation of ganglion nerve cells in aplysia. Biomedical science instrumentation, vol. I, p. 347-357 (F. ALT, Ed.). New York: Plenum Press 1963. - Poggro, G. F., and L. J. Viennstein: Time series analysis of impulse sequences of thalamic somatic sensory neurons. J. Neurophysiol. 27, 517-545 (1964). - RAPOPORT, A.: Contributions to the probabilistic theory of neural nets: II. Bull. Math. Biophys. 12, 187-197 (1950). Ter Hoopen, M.: On an impulse interval generating mecha. nism. Jap. J. Physiol. 14, 607-614 (1964a); — On a waiting time problem in physiology. Naturwissenschaften $\mathbf{5} 1,512-513$ (1964b). - Ten Hoopen, M., and H. A. Reuver: Unpublished results (1965a); - Selective interaction of two independent recurrent processes. J. appl. Prob. (1965b) (in press); - An $n$-fold coincidence problem in physiology. J. theor. Biol. (1965c) (in press.).

Address: M. Ten Hoopen, Institute of Medical Physics TNO Utrecht, The Netherlands Da Costakade 45

\title{
Oscillations in the Amplitude of Human Peripheral Nerve Action Potentials During Repetitive Stimulation*
}

\author{
WILLIAM R. UTTAL \\ University of Michigan \\ With 4 Figures in the Text \\ (Received June 25, 1965)
}

Summary. Repetitive stimulation of human peripheral nerves in situ produces an amplitude oscillation of the evoked action potentials. The purpose of this experiment was to describe the dynamics of the response as a function of the characteristics of the electrical stimuli. Two attempts to define precisely the origin of the response have proved ineffective.

* These studies were supported in part by Grant MH 8786-01 from the National Institute of Health and in part by Grant GR 2000 from the National Science Foundation. The author gratefully acknowledges the assistance of Mrs. MADELON KRISSOFF in the analysis of the data.
Oscillatory phenomena produced by impulsive stimulation of sensory systems have been observed by a number of investigators. Central nervous system structures seem to most clearly show these effects (Rosner, 1956; KEIDEL, KeIDEL, and Wigand, 1961). After potentials in presynaptic peripheral nerves following electrical stimulation have also been shown to display oscillatory behavior (GASSER and GRUNDFEST, 1936). LaRrabeE and Bronk (1947) have also shown 
that oscillations in the amplitude of the compound action potentials occur in postsynaptic nerve tracts in the sympathetic nervous system. However, the response amplitude of presynaptic compound action potentials seems generally to be considered to decrease without oscillation or not to change at all during repetitive stimulation (see Fig. 12 in KEIDEL, KEIDEL, and Wigand, 1961 ; Fig. 3 in Larrabee and Bronk, 1947; and Fig. 5 in Gasser and Grundwest, 1936). These results suggest that oscillations in response amplitude are introduced into the response waveform by synaptic action. Eccles (1952) has discussed the relationship of such phenomena to similar long term effects of perception and learning. He suggests that long term oscillations may be sensitive electrophysiological indicants of behavior and provide a means of exploring behavioral plasticity and perception in a delicate fashion.

Some earlier work in our laboratory with widely separated stimulus doublets (BRown, 1960) suggested that there may be long term effects generated by stimulation of human peripheral nerves in situ. The present paper presents the results of two studies of the dynamics of the peripheral compound action potentials recorded percutaneously from the human ulnar nerve when stimulated by trains of electrical pulse stimuli. Oscillations in the response amplitudes are shown to occur. This paper deals particularly with the functional relation of this oscillation to variations in stimulus amplitude and interpulse interval.

The data reported in this paper are for three male Ss. Our general technique is a modification of DAwsON and ScoTT's (1949) and has been described in detail elsewhere (UTTAL, 1959). In particular, pulse electrical stimuli were applied to the superficial point of the ulnar nerve at the wrist and compound action potentials recorded at the superficial point of the same nerve above the elbow. Stimuli pulses were 0.5 milliseconds in duration and the interval and amplitude varied according to the designs of the experiments described below.

Two experiments will be reported in this paper. The first investigated the effects of variation of the magnitude of the repetitive stimulus pulses on the envelope of response amplitudes. The second experiment investigated the effects of variation of the frequency of the stimulus train on this envelope.

In the first experiment, the Ss were stimulated with a train of constant current pulses which were separated by $12 \mathrm{~ms}$. intervals for a period of $200 \mathrm{~ms}$. The amplitude of the pulses in a given train was varied to include the following current levels: $1,2,3,4,5$, 6,7 , and 8 milliamperes. One set of records was taken for each of the Ss for each of the current levels.

In the second experiment, the Ss were stimulated with a train of constant intensity stimuli. The particular constant current varied for each $S$ but was in the range of 2.5 to 3.5 milliamperes. The parameter varied in this experiment was the interval between the sequential pulses. A given train would have an interval selected from the following set: $8,10,12,16$, $18,20,25,30$, and 40 milliseconds; but, as in the first experiment, the total duration of the sequence of pulses was limited to 200 milliseconds. One set of records was taken for each of the $\mathrm{Ss}$ in this experiment for each interval.
The oscillations in the amplitude of the peripheral nerve response exhibit great regularity. At first, some consideration was given to the fact that these responses might be artifacts of the electronic recording or stimulating systems rather than true neuroelectrical phenomena. A number of control tests were therefore made to minimize the possibility that any electrical artifacts were contributing to the response waveform. The first test was simple monitoring of the stimulus current as applied to the skin. The current through the electrodes was monitored by observing the voltage across a $100 \mathrm{ohm}$ precision resistor placed in series with the stimulating electrodes. The stimuli were shown by this technique to remain constant throughout the entire $200 \mathrm{~ms}$. period. Manipulations were than made
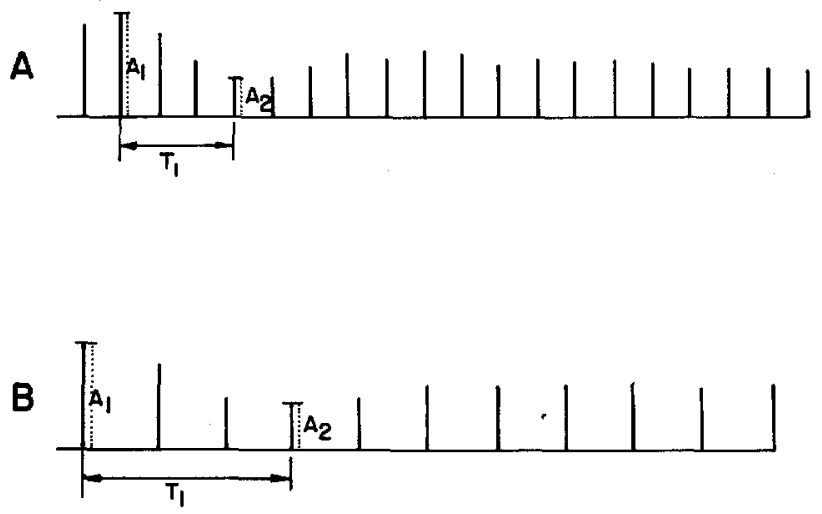

Fig. 1. Schematic drawing of the oscillatory response showing the two different measurement eriteria used for the two different types of response

on the characteristics of the recording amplifiers including alteration of the upper and lower band pass characteristics of the two A.C. coupled amplifiers and reversal of the leads from the recording and stimulating electrodes. In no case was an alteration made of the relative amplitudes of the responses. A further control implicit in the experiment is that the oscillation of the peripheral nerve response is at a maximum when the muscular twitch which accompanies this electrical response is at a minimum. This makes it extremely unlikely that we are dealing with some simple alteration of the sensitivity of the recording electrode due to a change in the impedance of the skin-electrode interface. This conclusion is further substantiated by the fact that, in those records in which the terminal end of the stimulus artifact could be observed, these ends were seen to be relatively invariant.

Several different measurements were taken as indicated in Fig. 1, a diagrammatic sketch of the two types of typical response. $A_{1}$ was the amplitude of the largest spike in the initial part of the response and varied from record to record as a measurement of the first, second, or third response, depending upon the stimulus interval. $A_{2}$ was the amplitude of the smallest spike in the first trough of amplitude. $T_{1}$ was the time from the beginning of the stimulus train to the minimum of the envelope. A pulse may or may not have been present at this minimum, depending upon the intervals of the pulses in the stimulus train.

An important derived measure was the peak to trough ratio which was defined as $A_{1} / A_{2}$ and which is independent of the amplitude of the response. Thus, a high peak to trough ratio indicated a considerable swing in the amplitude of the response, but does not 
differentiate between large or small absolute amplitudes.

Fig. 2 shows a $200 \mathrm{~ms}$. typical sample of the series of responses to a repetitive train of stimuli. The upward going spikes are the nerve response and the lower

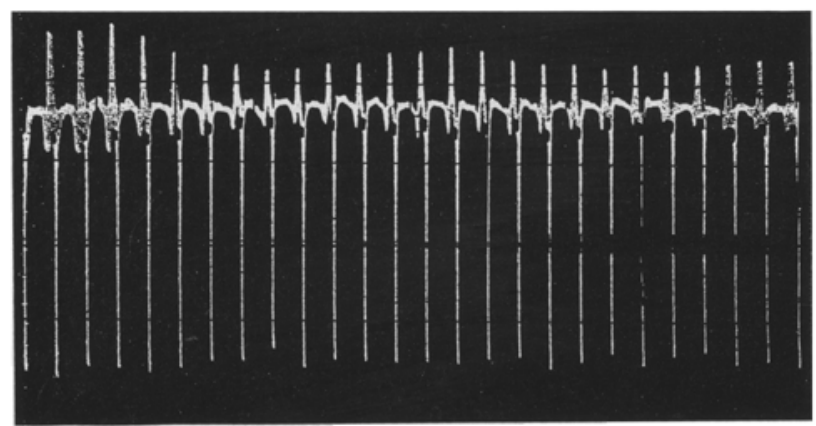

Fig. 2. A $200 \mathrm{~ms}$. long stimulation period showing the repetitive socillations ( 200 volts full scale vertical)

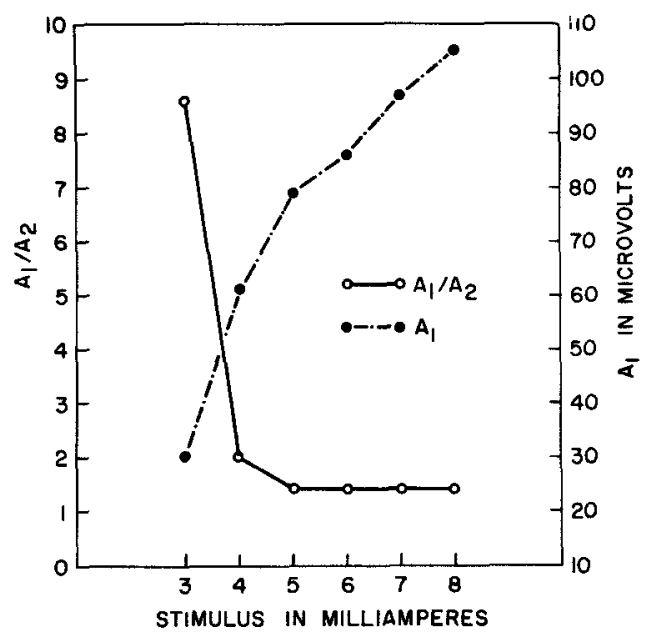

Fig. 3. Pooled data for all Ss showing the effect of stimulus intensity increase on the absolute amplitude of $A_{1}$ and the peak to trough ratio $A_{1} / A_{2}$

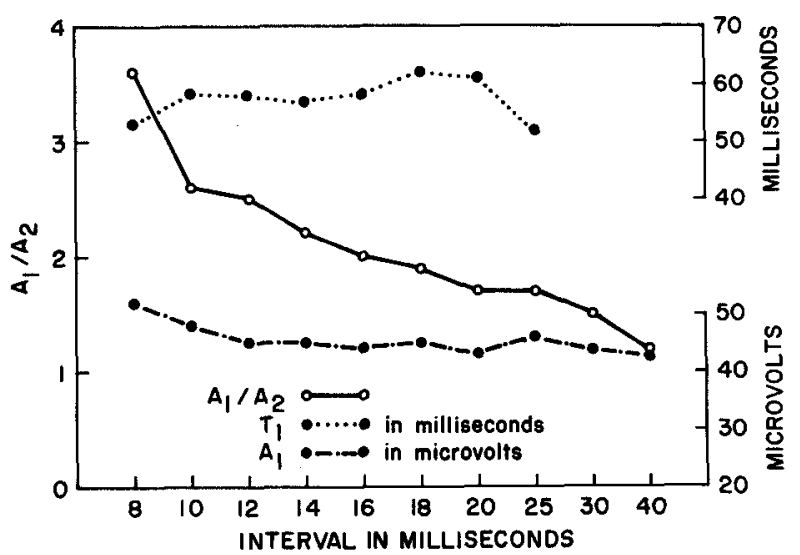

Fig. 4. Pooled data for all Ss showing the effects of increasing stimulus interval on peak to trough ratio $A_{1} / A_{2}$, the time to the first trough, $T_{1}$, and the absolute amplitude at $A_{1}$

the stimulus artifacts. It can be seen that there is an oscillation of the amplitude of the responses as a function of serial position which lasts for a considerable period of time. In some records this oscillation may appear to continue for 300 or 400 milliseconds. But, like many damped oscillations, it appears that successive amplitude swings are progressively smaller.

As the stimulus amplitude is increased, the following sequence of events was exhibited by all subjects.
Responses cannot be distinguished from noise for stimulus amplitudes of 1 and 2 ma., but begin to emerge at about 3 ma. At 4 milliamperes, all responses were clearly visible and the oscillation peak to trough ratio was most clear. Above this stimulus intensity the size of the responses continues to increase, but the ratio of peak to trough amplitudes decreases. In general there appeared to be no change in $T_{1}$ - the time at which the first trough appears. All Ss showed this same pattern. Differences between Ss were, however, observed in the stimulus intensity at which the responses appeared. The steady increase of $A_{1}$ as stimulus intensity is increased and the steady decrease in $A_{1} / A_{2}$ during this same variation are plotted in Fig. 3 with data pooled for all Ss.

Because of the variation in threshold at which the responses emerge, stimulus intensity in the second experiment was adjusted individually for each subject. Fig. 4 shows the pooled data for all subjects in all trials in which the stimulus interval was varied and the amplitude held constant. Thus, each plotted point represents the average of six measurements. The amplitude of $A_{1}$ remains constant over the entire range of intervals studied. The peak to trough ratio $A_{1} / A_{2}$, however, shows a gradual decline as the interpulse interval is increased. This decline, however, does occur for a trough with $T_{1}$ essentially constant regardless of interpulse interval as can be seen from the other curves in this figure.

Inspection of superimposed responses revealed no change in the latencies of the responses during the repetitive stimulus burst.

In this experiment we are dealing with an oscillation of response amplitude which occurs during tetanic stimulation rather than the recovery effects which follow the tetanus. LARRABEE and Bronk's (1947) study of sympathetic ganglia is the only other observation of oscillation during a tetanus to have come to our attention. Their study shows a similar oscillation but only when the stimulus is applied to the presynaptic neurons and the response recorded from postsynaptic ones. If the stimulator is then moved to the post-synaptic tract, the responses are flat during the tetanus and the post-tetanic potentiation (PTP) is absent. This suggests that these oscillatory phenomena may be related to synaptic action.

We are faced with the question of the origin of the oscillatory potentials in our records. There are two principal hypotheses which remain once we exclude artifacts of technique and accept these oscillations as true neurophysiological events. The first assumes that the oscillation is due to the changes in the nerve membrane potentials which occur during tetanic stimulation. Thus, the oscillation could reflect the collective "hunting" of the involved nerve membrane potentials for new equilibrium levels. The oscillation would be related in this case to refractory periods and a non-monotonic accumulation of after potentials during the repetitive train of stimulations.

The second hypothesis assumes that the effect is not a function of the nerve membrane dynamics of the stimulated nerves but rather is a result of reflexively generated centrifugal activity by spinal or higher centers. Thus, in this case, efferent activity would be assumed to be interfering with the afferent activity represented by this compound action potential. 
The existence of such reflexive activity has been established. ToEnNIEs (1938) has described a dorsal root reflex of sensory fibers in which spike action potentials are reflected back along the same afferent fibers which conveyed the nerve impulse away from the point of stimulation. Fullerton and GilliatT (1965) have more recently reported another axon reflex which appears to be produced at branch points in efferent fibers stimulated antidromically. The fact that the effect reported in this present experiment was more pronounced at the low stimulus intensities at which sensory fibers are more likely to be excited (DAwson, 1956) suggests that the dorsal root reflex is a more likely explanation if a feedback explanation ultimately proves to be more appropriate.

To test these hypotheses two additional experiments were attempted. The first was performed on the same human subjects used in the earlier parts of the experiment and simply involved switching the stimulation and recording electrodes. Thus, stimulation was applied above the elbow and it was hoped that recordings would be made at the wrist. Unfortunately, the ulnar nerve at the elbow has a very large motor component feeding much of the forearm. Electrical stimulation at the elbow, therefore, produces a massive motor response in the forearm and the resulting electromyogram completely masks the nerve action potentials. This attempt was, therefore, ineffective.

The second additional experiment was an attempt to replicate and then surgically manipulate these oscillations in the analogous ulnar nerve of two cats. The ulnar nerve was exposed at the two superficial points on the cat's upper limb. Stimuli were applied to the lower point and responses recorded from the upper point. It proved impossible to replicate the oscillatory phenomenon found in man in the cat, and this experiment also proved to be ineffective as a means of resolving the question of origin.
The basic characteristics of this response suggest a feedback explanation of this phenomenon. The insensitivity of the wavelength of the oscillation to stimulus interval variation suggests that a constant factor such as transmission time from point of stimulation to the point of interaction is involved. A nerve membrane hypothesis would probably involve a frequency sensitivity as more and more frequent stimuli produced cumulative effects in the after potentials.

References. Brown, J. E.: A parametric study of neuroelectric responses to skin stimuli. Thesis submitted to Dept. of Electrical Engineering, MIT, 1960. - Dawsor, G. D.: The relative excitability and conduction velocity of sensory and motor nerve fibres in man. J. Physiol. (Lond.) 131, 436-451 (1956). - Dawsor, G. D., and J. W. ScotT: The recording of nerve action potentials through skin in man. J. Neurol. Psychiat. 12, 259-267 (1949). - EccLEs, J. C.: The neurophysiological basis of mind, the principles of neurophysiology. Oxford: Clarendon Press 1952. - Eccles, J. C., and K. KRNJEvIc: Presynaptic changes associated with post-tetanic potentiation in the spinal cord. J. Physiol. (Lond.) 149, 274-287 (1959). - Fullerton, P. M., and R. W. GmLiatt: Axon reflexes in human motor nerve fibres. J. Neurol. Neurosurg. Psychiat. 28, 1-11 (1965). - Gasser, H. S., and H. GrundFEST: Action and excitability in mammalian a fibers. Amer. J. Physiol. 117, 113-133 (1936). - Larrabee, M. G., and D. W. Bronk: Prolonged facilitation of synaptic excitation in sympathetic ganglia. J. Neurophysiol. 10, 139-154 (1947). Kerdel, W. D., U. O. KatdeL, and M. E. Wigand: Adaptation: Loss or gain of sensory information? In: W. A. RoserBLITH (Ed.), Sensory communication, p. 319-338. Cambridge (Mass.): MIT Press; and New York and London: John Wiley \& Sons 1961. - Rosner, B. S.: Effects of repetitive peripheral stimuli on evoked potentials of somatosensory cortex. Amer. J. Physiol. 187, 175-179 (1956). - Tonndies, J. F.: Reflex discharge from the spinal cord over the dorsal roots. J. Neurophysiol. 1, 378 - 390 (1938). - UTTAL, W. R.: A comparison of neural and psychophysical responses in the somesthetic system. J. comp. physiol. Psychol. 52, 485-490 (1959).

Address: Prof. W. R. UtтAL

Mental Health Research Institute

The University of Michigan

Ann Arbor/Michigan (USA)

\title{
Ein elektronisches Funktionsmodell für Verhaltensweisen eines Fisches
}

\author{
G. HAuske, München \\ Aus dem Institut für Nachrichtentechnik der Technischen Hochschule München (Direktor: Prof. Dr.-Ing. H. Marko) \\ Mit 12 Textabbildungen
}

(Eingegangen am 2. Juli 1965)

\begin{abstract}
Summary. This paper is concerned with a model for the interaction of certain behaviour patterns of a fish (Pelmatochromis subocellatus kribensis BOUL; Cichlidae). Five behaviour patterns (schooling behaviour, locomotion, biting, fleeing, camouflaging) are described as a function of four external stimulus patterns $\left(\mathrm{CO}_{2}\right.$-concentration, school-signal, conspecific's signal, frightening-signal) and three so-called internal states of readiness (readiness to school, readiness to attack with bites, responsiveness to frightening stimuli). In accordance with the statistical appearance of behaviour patterns the model contains five interdependent statistical pulse generators. This model is planned to find and to confirm a theory for a quantitative description of behaviour patterns, the interdependencies of which give a representation of the internal structure of the organism.
\end{abstract}

\section{Einleitung}

Auf der vom NTG-Fachausschuß 1 am 30./31. 10. 1963 im Institut für Nachrichtentechnik der Technischen Hochschule München veranstalteten Diskussionssitzung,,Stochastische Vorgänge in der Biologie" berichtete HeILIGenberg über das Instinkt- verhalten von Fischen (Pelmatochromis subocellatus kribensis BouL., Cichlidae). Er stellte dabei ein Blockschaltbild auf (leicht vereinfachte Darstellung in Abb. 8), das aus der Korrelation der Häufigkeit verschiedener Verhaltensweisen entwickelt wurde und einen qualitativen Zusammenhang dieser Häufigkeiten mit Reizsignalen und den sog. Bereitschaften beschreibt [1]. Diese Zusammenhänge stellen eine Abbildung von Vorgängen und Gesetzmäßigkeiten im tierischen Organismus dar, soweit Verhaltensweisen davon abhängen. In der Diskussion entstand der Wunsch, dieses System durch ein elektronisches Funktionsmodell nachzubilden, um seine Realisierbarkeit zu prüfen und möglicherweise weitere Erkenntnisse für eine zweckmäßige Beschreibung quantitativer Eigenschaften von Verhaltensweisen zu gewinnen. Im Rahmen einer Diplomarbeit wurde ein solches Modell vom Verfasser entwickelt und seine Funktion mit den am Tier gewonnenen Ergebnissen verglichen. 